\title{
Progranulin Suppressed Autoimmune Uveitis and Autoimmune Neuroinflammation by Inhibiting Th1/Th17 Cells and Promoting Treg Cells and M2 Macrophages
}

Chaokui Wang, PhD, * Wenjun Zhou, PhD,* Guannan Su, PhD, Jianping Hu, and Peizeng Yang, PhD

Neurol Neuroimmunol Neuroinflamm 2022;9:e1133. doi:10.1212/NXI.0000000000001133

\author{
Correspondence \\ Dr. Yang \\ peizengycmu@126.com
}

\section{Abstract}

\section{Background and Objectives}

Progranulin (PGRN) is an important immune regulatory molecule in several immunemediated diseases. The objective of this study is to investigate the role of PGRN in uveitis and its counterpart, experimental autoimmune uveitis (EAU), and experimental autoimmune encephalomyelitis (EAE).

\section{Methods}

Serum PGRN levels in patients with Behcet disease (BD) or Vogt-Koyanagi-Harada (VKH) disease and normal controls were measured by ELISA. EAE and EAU were induced in B10RIII, wild-type, and $\mathrm{PGRN}^{-/-}$mice to evaluate the effect of PGRN on the development of these 2 immune-mediated disease models. The local and systemic immunologic alterations were detected by ELISA, flow cytometry, and real-time PCR. RNA sequencing was performed to identify the hub genes and key signaling pathway.

\section{Results}

A significantly decreased PGRN expression was observed in patients with active BD and active VKH. Recombinant PGRN significantly reduced EAU severity in association with a decreased frequency of Th17 and Th1 cells. PGRN ${ }^{-/-}$mice developed an exacerbated EAU and EAE in association with strikingly increased frequency of Th1 and Th17 cells and reduced frequency of regulatory $\mathrm{T}$ (Treg) cells. In vitro studies revealed that $\mathrm{rPGRN}$ could inhibit IRBP ${ }_{161-180^{-}}$ specific Th1 and Th17 cell response and promote Treg cell expansion. It promoted nonantigen-specific Treg cell polarization from naive $\mathrm{CD} 4^{+} \mathrm{T}$ cells in association with increased STAT5 phosphorylation. Using RAN sequencing, we identified 5 shared hub genes including Tnf, Il6, Il1b, Cxcl2, and $C c l 2$ and the most significantly enriched MAPK and tumor necrosis factor signaling pathway in PGRN ${ }^{-/-}$EAU mice. The aggravated EAE activity in PGRN ${ }^{-/-}$ mice was associated with a skew from M2 to M1 macrophages.

\section{Discussion}

Our results collectively reveal an important protective role of PGRN in EAU and EAE. These studies suggest that PGRN could serve as an immunoregulatory target in the study of prevention and treatment for the Th1/Th17-mediated diseases.

*These authors contributed equally to this study and should therefore be regarded as co-first authors.

From the First Affiliated Hospital of Chongqing Medical University, Chongqing Key Lab of Ophthalmology, Chongqing Eye Institute, Chongqing Branch of National Clinical Research Center for Ocular Diseases, China.

Go to Neurology.org/NN for full disclosures. Funding information is provided at the end of the article. 


\section{Glossary}

Arg-1 = arginase 1; BD = Behcet disease $\mathbf{D E G s ~}=$ differentially expressed genes; $\mathbf{E A E}=$ experimental autoimmune encephalomyelitis; EAU = experimental autoimmune uveitis; ERK = extracellular signal-regulated kinase; GO = gene ontology; GSEA = gene set enrichment analysis; IFN = interferon; IL = interleukin; iNOS = inducible nitric oxide synthase; JNK = Jun Nterminal kinase; KEGG = Kyoto Encyclopedia of Genes and Genomes; MAPK = mitogen-activated protein kinase; $\mathbf{M C P}=$ monocyte chemoattractant protein; mRNA = messenger RNA; MS = multiple sclerosis; PGRN = progranulin; RNA-seq = RNA sequencing; RT-PCR = real-time PCR; Th = T helper; TNF = tumor necrosis factor; Treg = regulatory T; VKH = VogtKoyanagi-Harada; $\mathbf{W T}=$ wild type.

It has been reported that up to $25 \%$ of cases of legal blindness in the developing world were implicated with uveitis. ${ }^{1,2}$ The characteristics of uveitis include blood-ocular barrier disruption and inflammatory effector T-cell recruitment from peripheral lymphoid tissues into the retina. ${ }^{3}$ The mechanisms underlying this disease have not been fully elucidated. Accumulating evidence demonstrates that interferon (IFN)- $\gamma$-producing T helper (Th1) and interleukin (IL)-17-producing (Th17) cells exert a critical role in autoimmune uveitis. ${ }^{4,5}$ In addition, our previous studies have found a decreased $\mathrm{CD} 4^{+} \mathrm{CD} 25^{+}$Foxp $3^{+}$regulatory $\mathrm{T}$ (Treg) cells contributed to the development of Vogt-KoyanagiHarada $(\mathrm{VKH})$ disease. ${ }^{6}$ All these results suggest that disturbed balance between inflammatory and Treg cells may underlie the pathogenesis of autoimmune uveitis. Experimental autoimmune uveitis (EAU) shares clinical and immunopathologic features with human uveitis. ${ }^{7}$ Numerous studies on EAU have focused on seeking out targets that can be used to inhibit autoreactive Th1 and Th17 cells or promote Treg cell immune response for the treatment of autoimmune uveitis.

Multiple sclerosis (MS) is a chronic and recurrent inflammatory disease of the CNS, largely similar to uveitis clinically. It is characterized by the neurodegeneration and demyelination. ${ }^{8}$ Experimental autoimmune encephalomyelitis (EAE) has long been used as a model for studying the pathogenesis of MS. Similarly, Th1 and Th17 are also known to be implicated in the development of MS and EAE. Macrophages play a crucial role in EAE and have 2 polarized subpopulations: proinflammatory M1 macrophages induced by IFN $-\gamma$ and immunomodulatory M2 macrophages induced by IL-4. A predominant skew of M1 macrophages has been observed in EAE, ${ }^{9}$ and the pathways or factors that could skew balance toward M2 macrophages have been proven to control the autoimmune inflammation by inhibiting pathogenic $\mathrm{CD} 4^{+} \mathrm{T}$ cells. ${ }^{10}$

Progranulin (PGRN) is abundantly expressed in immune cells, neurons, epithelial cells, and chondrocytes. ${ }^{11}$ PGRN plays a crucial role in several physiologic and pathologic processes including wound healing, neurodegeneration, tumorigenesis, and infection. ${ }^{12-14}$ Recently, PGRN has been reported to have anti-inflammatory functions. Studies on collagen-induced arthritis revealed a higher susceptibility and server inflammatory activity in PGRN ${ }^{-/-}$mice. ${ }^{14}$ However, the study with lupus nephritis have showed that PGRN could significantly exacerbate the disease activity. ${ }^{15}$ Collectively, these findings suggest that PGRN may exert different roles in different physiopathologic conditions. However, the role of PGRN in the autoimmune uveitis is still unknown. Inflammation involving small vessels is a typical feature of Behcet disease (BD). Involvement of retinal blood vessels, as evidenced by vascular leakages on fluorescein fundus angiography, may also be observed in VKH disease. ${ }^{16}$ EAU has long been used as a model in the study of the mechanisms implicated in both diseases. EAU and EAE have some features in common, such as induction with specific antigen, overactivation of Th17 and/or Th1 cells, and decreased Treg cells. ${ }^{17}$ In addition, both BD and VKH diseases may cause inflammation in the CNS. In this study, we investigated the effect of PGRN on both autoimmune-driven inflammatory disease models and possible mechanisms involved in them.

\section{Methods}

Details of all methods are provided in eMethods (links.lww. com/NXI/A687).

\section{Standard Protocol Approvals, Registrations, and Patient Consents}

All the patients fulfilled the international criteria for the diagnosis of $\mathrm{BD}^{18}$ and $\mathrm{VKH},{ }^{19,20}$ respectively. All the patients signed the informed consent forms, and this study adhered to the tenets of Declaration of Helsinki and was approved by the Ethical Research Committee of The First Affiliated Hospital of Chongqing Medical University.

All mice were treated in strict adherence with the Institutional Animal Care and Use Committee's guidelines at the Chongqing Medical University. In this study, the ARRIVE reporting guidelines were used. ${ }^{21}$

\section{Statistical Analysis}

All data were expressed as mean \pm SEM. Statistical calculations of the cell frequency, cytokine expression, and clinical and histologic analysis were performed with the unpaired Student $t$ test or Mann-Whitney test (2 tailed). The difference of serum PGRN in normal controls and patients was performed with independent-samples $t$ test. The differences were considered statistically significant at $p<0.05$. 


\section{Data Availability}

Data not shown in this article because of space limitations can be shared if requested by other investigators for purposes of replicating procedures and results.

\section{Results}

\section{Expression of PGRN Is Decreased in Both aBD and aVKH}

The serum level of PGRN in patients with $\mathrm{aBD} / \mathrm{aVKH}$ and normal controls was assessed using ELISA, and the results showed a decreased expression of PGRN in the serum from $\mathrm{aBD}$ or aVKH compared with normal controls (Figure 1, A and B). A similar result was also observed in the gene expression of PGRN in peripheral blood mononuclear cells (Figure 1, C and D) and monocyte-derived DCs (eFigure 1, links.lww.com/NXI/A687) from patients and controls.

\section{Recombinant PGRN Ameliorates EAU and Inhibits Th1 and Th17 Effector Responses In Vivo}

To investigate the function of PGRN in vivo, we examined the expression of PGRN in the isolated retina tissues from the EAU mice. Our results showed that there was a substantial increase of the PGRN gene expression in the retina on day 14 and a rapid decrease on day 21 (Figure 2A). This upregulated PGRN gene expression may be responsible for the rapid regression of EAU as seen on day $21 .^{22}$
We induced EAU in B10RIII mice with or without administration of recombinant PGRN. The results showed that PGRN-treated mice showed a significantly lower clinical score and reduced vasculitis and cell infiltration in the retina compared with the phosphate-buffered saline-treated mice (Figure 2B and eFigure 2A, links.lww.com/NXI/A687). To investigate the mechanisms involved in the protective role of PGRN in EAU, splenocytes were harvested on day 13 for the detection of Th1, Th17, and Treg frequency and detection of cytokines. The results showed a significantly decreased frequency of IL-17 $\mathrm{A}^{+} \mathrm{CD} 4^{+} \mathrm{T}$ cells and IFN- $\gamma^{+} \mathrm{CD} 4^{+} \mathrm{T}$ cells in the spleen from PGRN-treated EAU mice. Consistently, a decreased messenger RNA (mRNA) level of IFN- $\gamma$ and IL-17 was found in the spleen from PGRN-treated EAU mice. However, there were no differences concerning the frequency of $\mathrm{CD} 4^{+} \mathrm{CD} 25^{+} \mathrm{Foxp}^{+} \mathrm{T}$ cells or the mRNA level of IL-10 and FoxP3 in the spleen between these 2 groups (Figure 2, C and $\mathrm{D}$ and eFigure $2 \mathrm{~B}$ ). In addition, we found a markedly decreased mRNA expression of IL-1 $\beta$, monocyte chemoattractant protein (MCP)-1 IL-6, tumor necrosis factor (TNF)- $\alpha$, IFN- $\gamma$, and IL-17 in the retina from PGRNtreated EAU mice (eFigure 2C).

\section{PGRN $^{-/-}$Mice Develop Exacerbated EAU}

To further identify the role of PGRN in EAU, wild-type (WT) and $\mathrm{PGRN}^{-1-}$ mice of C57BL/6 background were used for induction of this model. The results showed that PGRN $^{-/-}$ mice developed more severe EAU compared with WT mice (Figure 3A). In addition, histologic analysis showed a more
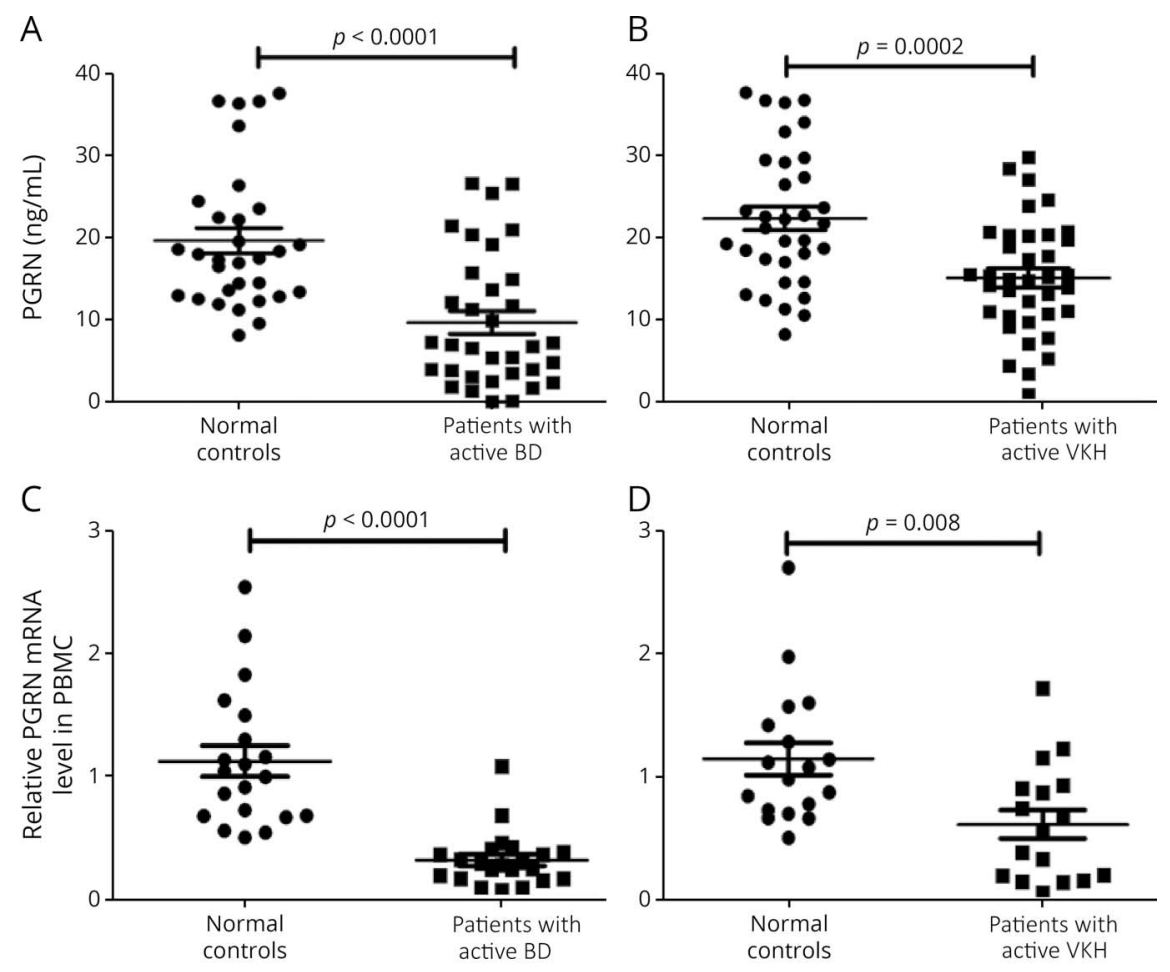

(A-B) PGRN levels were detected by ELISA in serum collected from patients and normal controls (A: 34 aBD patients VS 31 normal controls, B: 37 aVKH patients VS 34 normal controls). (C-D) PGRN mRNA expression was measured by RTPCR in PBMCs from patients and normal controls. (C: 22 aBD patients VS 20 normal controls, D: 17 aVKH patients VS 18 normal controls). Data are expressed as mean \pm SEM, and dots represent individual participants. Mann-Whitney $U$ tests or independent $t$ tests were used for statistical analyses. $\mathrm{BD}=$ Behcet disease; $\mathrm{mRNA}=$ messenger RNA; $P$ GRN = progranulin; $R T-P C R=$ real-time PCR; VKH = Vogt-Koyanagi-Harada. 


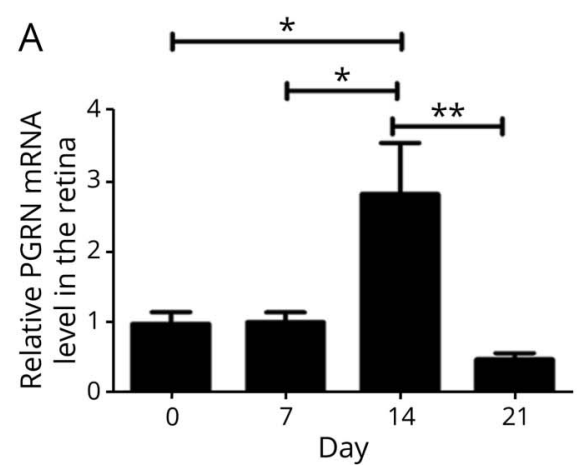

C

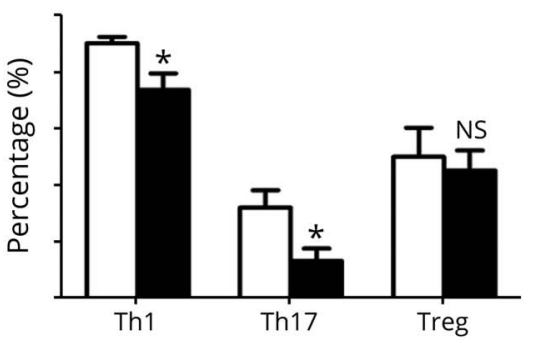

B

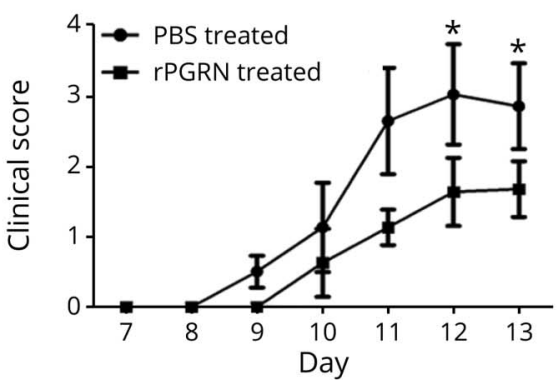

D

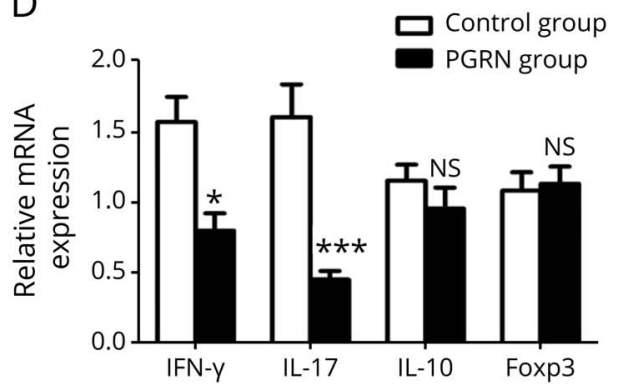

(A) Quantitative RT-PCR analysis of PGRN expression in the retinal tissues from EAU mice at different time points after immunization. (B) B10RIII mice were immunized for EAU and injected intraperitoneally with rPGRN or PBS every other day from days 7-13 postimmunization. Quantification of clinical score of 2 EAU groups from day 7 to day 13 after immunization was shown. (C) Quantification of intracellular expression of IL-17, IFN-y, and $\mathrm{CD}_{25}{ }^{+} \mathrm{Foxp}^{+}$by $\mathrm{CD} 4^{+} \mathrm{T}$ cells (Th1, Th17, and Treg, respectively) in the spleen from the 2 groups. (D) Quantitative RT-PCR analysis of IFN$y, I L-17, I L-10$, and foxp3 in the splenocytes from PGRN- or PBS-treated mice after immunization on day 13. Data are shown as mean \pm SEM from 2 to 3 independent experiments with total of 10 mice per group. ${ }^{\star} p<0.05,{ }^{*} p<0.01,{ }^{*} * * p<$ 0.001 , and NS, not significant. EAU = experimental autoimmune uveitis; IL = interleukin; IFN = interferon; PBS = phosphate-buffered saline; PGRN = progranulin; RT-PCR = real-time PCR; Th $=\mathrm{T}$ helper; Treg $=$ regulatory $\mathrm{T}$. severe vasculitis and inflammatory cell infiltration within the eye from $\mathrm{PGRN}^{-/-}$mice (Figure $3 \mathrm{~B}$ and eFigure $3 \mathrm{~A}$, links. lww.com/NXI/A687).

A further experiment was designed to detect the mechanisms underlying the effect of the deficiency of PGRN on EAU. The results showed a significantly higher frequency of $\mathrm{IL}-17 \mathrm{~A}^{+} \mathrm{CD} 4^{+}$ $\mathrm{T}$ cells and IFN- $\gamma^{+} \mathrm{CD} 4^{+} \mathrm{T}$ cells and lower frequency of $\mathrm{CD} 4^{+} \mathrm{CD} 25^{+} \mathrm{Foxp}^{+} \mathrm{T}$ cells in the spleen from $\mathrm{PGRN}^{-/}$EAU mice compared with WT EAU mice (Figure $3 \mathrm{C}$ and eFigure 3B, links.lww.com/NXI/A687). Consistently, real-time PCR (RTPCR) analysis showed a higher mRNA expression of IFN- $\gamma$ and IL-17 and a decreased mRNA levels of IL-10 and Foxp3 in the spleen from $\mathrm{PGRN}^{-/-}$EAU mice (Figure 3D). Furthermore, we found significantly higher levels of IFN- $\gamma$ and $\mathrm{IL}-17$ and lower levels of IL-10 in the retina of $\mathrm{PGRN}^{-/-}$mice compared with WT mice (eFigure 3C).

\section{Recombinant PGRN Inhibits Antigen-Specific Th1/Th17 and Promotes Antigen-Specific Treg Cell Expansion and Non-Antigen-Specific Treg Cell Differentiation In Vitro}

The aforementioned results showed that the deficiency of PGRN could lead to a higher frequency of Th1/Th17 cells and a lower frequency of Treg cell in EAU. A further experiment was designed to examine whether rPGRN specifically regulated IRBP peptide-induced immune response. Spleen cells from EAU mice of C57BL/6 background were stimulated with IRBP $651-670$ peptide in the presence or absence of rPGRN. The results showed that the administration of rPGRN could directly inhibit the frequency of $\mathrm{IL}-17 \mathrm{~A}^{+} \mathrm{CD} 4^{+}$
$\mathrm{T}$ cells and IFN- $\gamma^{+} \mathrm{CD} 4^{+} \mathrm{T}$ cells in association with upregulation of $\mathrm{CD}^{+} \mathrm{Foxp}^{+} \mathrm{T}$ cells in vitro (Figure 4, A and B).

To examine the effect of PGRN on T-cell differentiation, naive $\mathrm{CD}^{+} \mathrm{T}$ cells from the spleen of normal C57BL/6 mice were cultured under Th1, Th17, or Treg cell polarization conditions in the presence or absence PGRN. The results showed that PGRN could induce $\mathrm{CD} 4^{+}$Foxp $3^{+} \mathrm{T}$-cell differentiation, but did not have any influence on Th1 and Th17 cell differentiation (Figure 4, C and D). In view of the critical role of STAT signaling activity in the differentiation of different Th cell subsets, we assessed the signaling activity of STAT in the Th cell differentiation. The results showed that naive $\mathrm{CD}^{+} \mathrm{T}$ cells under Treg polarization condition and in the presence of PGRN had an increased STAT5 phosphorylation (eFigure 4, links.lww.com/NXI/A687).

\section{Identification of Hub Genes and Pathways Involved in the Exacerbated Uveitis in PGRN ${ }^{-1-}$ Mice by RNA Sequencing}

We investigated the key genes and pathways involved in the exacerbated EAU in $\mathrm{PGRN}^{-/-}$mice using RNA sequencing (RNA-seq). The principal component analysis showed a significantly different gene expression profiles between $\mathrm{PGRN}^{-/-}$EAU and WT EAU (eFigure 5, A and B, links.lww. com/NXI/A687). A total of 226 differentially expressed genes (DEGs) in the spleen and 160 DEGs in the retina were identified from PGRN $^{-/-}$EAU mice compared with WT EAU (eFigure 5, C and D). The volcano plots of DEG in the spleen and retina between the 2 groups are illustrated in Figure 5A. A total of 13 DEGs were shared in the spleen and retina 

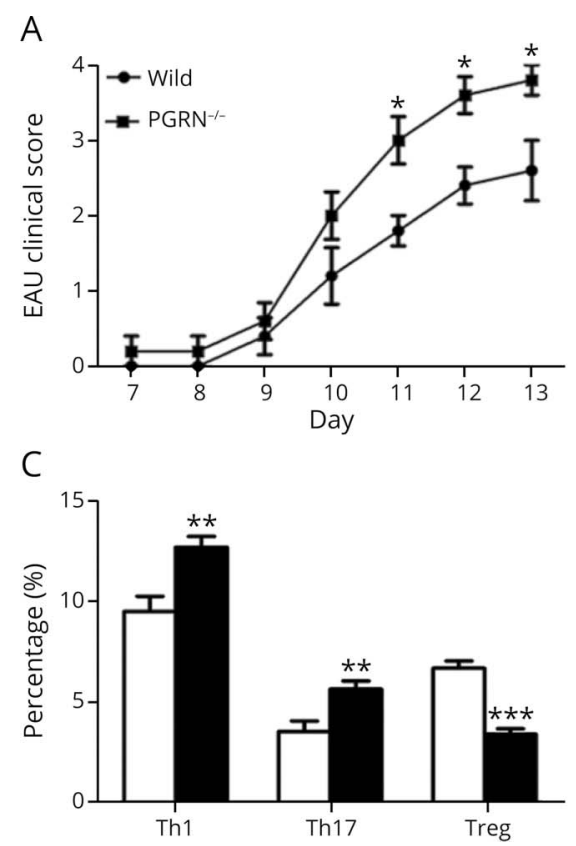
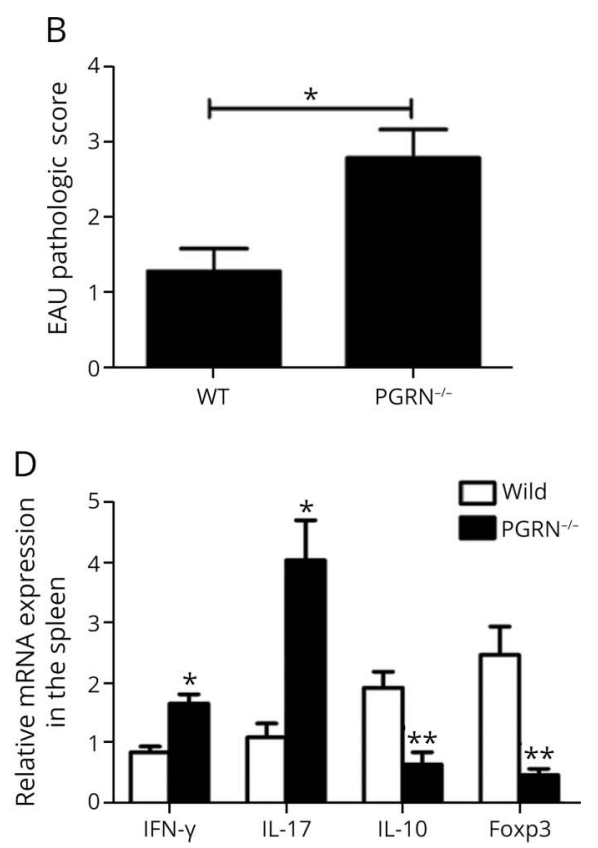

WT and PGRN ${ }^{-1-}$ mice of C57BL/6 background were induced for EAU. (A) Quantification of clinical score of the 2 groups from day 7 to day 13. (B) Pathologic scores of the 2 EAU groups on day 13. (C) Detection of intracellular expression of IL-17, IFN-y, and Foxp3 by CD4 ${ }^{+} \mathrm{T}$ cells in spleen by flow cytometry. (D) Quantitative RTPCR analysis of IFN-y, IL-17, IL-10, and foxp3 in the splenocytes. Data are shown as mean \pm SEM from 2 to 3 independent experiments with a total of 10 mice per group. ${ }^{\star} p<0.05,{ }^{* \star} p<0.01$, and $* * * p<0.001$. EAU $=$ experimental autoimmune uveitis; IL = interleukin; IFN = interferon; PGRN = progranulin; RT-PCR = real-time PCR; Th $=\mathrm{T}$ helper; $\mathrm{WT}=$ wild type.
(Figure 5B), which were Lcn2, Chil1, Tnf, Rac2, Hp, Cd14, Steap4, Il6, Cxcl2, F10, Ccl2, Illb, and S100a8, respectively.

We conducted gene ontology (GO) and Kyoto Encyclopedia of Genes and Genomes (KEGG) analysis for DEGs using DAVID online software. GO enrichment analysis showed that the enriched GO terms both in the spleen and in the retina were mostly involved in inflammatory response, immune response, and signaling pathway transduction (eFigure 6, links. lww.com/NXI/A687). KEGG enrichment pathway analysis showed that the DEGs were mostly enriched in mitogenactivated protein kinase (MAPK) signaling pathway and TNF signaling pathway in the spleen and mostly involved in cytokine-cytokine receptor interaction pathway and TNF signaling pathway in the retina (eFigure 7).

We further performed gene set enrichment analysis (GSEA) to identify meaningful signaling pathway. The GSEA results showed a 5 top-ranked enriched upregulated and 3 topranked enriched downregulated gene sets in the spleen as well as the top 5 enriched upregulated and the top 5 enriched downregulated gene sets in the retina (Figure 5, C and D). Collectively, both KEGG analysis and GSEA showed that MAPK signaling pathway and cytokine and cytokine receptor interaction pathway were the most significantly enriched pathway in the spleen and retina, respectively. Importantly, the shared most significantly enriched pathway in both the spleen and the retina was TNF signaling pathway.

To identify the hub gene in the process of the exacerbation of uveitis in PGRN ${ }^{-1-}$ mice, the PPI network for DEGs in the spleen and retina was constructed using STRING database (eFigure 8, A and C, links.lww.com/NXI/A687). Hub genes were then screened and identified by Cytoscape MCODE. The results showed that 24 hub genes in the spleen and $23 \mathrm{hub}$ genes in the retina were identified (eFigure 8, B and D). Five overlapping hub genes including Tnf, Il6, Illb, Cxcl2, and $C c l 2$ were all upregulated in both the spleen and the retina (eFigure $8 \mathrm{E}$ ). The 5 overlapping hub genes in both the spleen and the retina were all validated by RT-PCR, showing an increased expression in both the spleen and the retina from PGRN $^{-/-}$EAU mice (eFigure 9, $A$ and $B$ ).

To verify the changes of MAPK signaling pathway in the spleen between PGRN ${ }^{-/-}$EAU mice and WT EAU groups, phosphorylation levels of MAPK p38, Jun N-terminal kinase (JNK), and extracellular signal-regulated kinase $1 / 2$ (ERK1/2) were assessed by flow cytometry. The results showed increased phosphorylation levels of p38 and JNK, but not ERK1/2, in the spleen from PGRN ${ }^{-/-}$EAU mice compared with WT EAU mice (eFigure 9C, links.lww.com/ NXI/A687).

\section{PGRN $^{-/-}$Mice Develop Exacerbated EAE}

The aforementioned results showed a protective role of PGRN in EAU. A further study was designed to investigate whether it had a similar effect on EAE. The results showed that PGRN $^{-/-}$EAE mice exhibited significantly severer inflammatory activity and a smaller body weight compared with WT EAE mice (Figure 6, A and B). Histopathologic analysis showed that the infiltration of inflammatory cells and demyelination were more severe in the brain from $\mathrm{PGRN}^{-/-}$ 
Figure 4 Recombinant PGRN Inhibits IRBP-Reactive Th1 and Th17 Cell Expansion and Promotes IRBP-Reactive Treg Cell Expansion
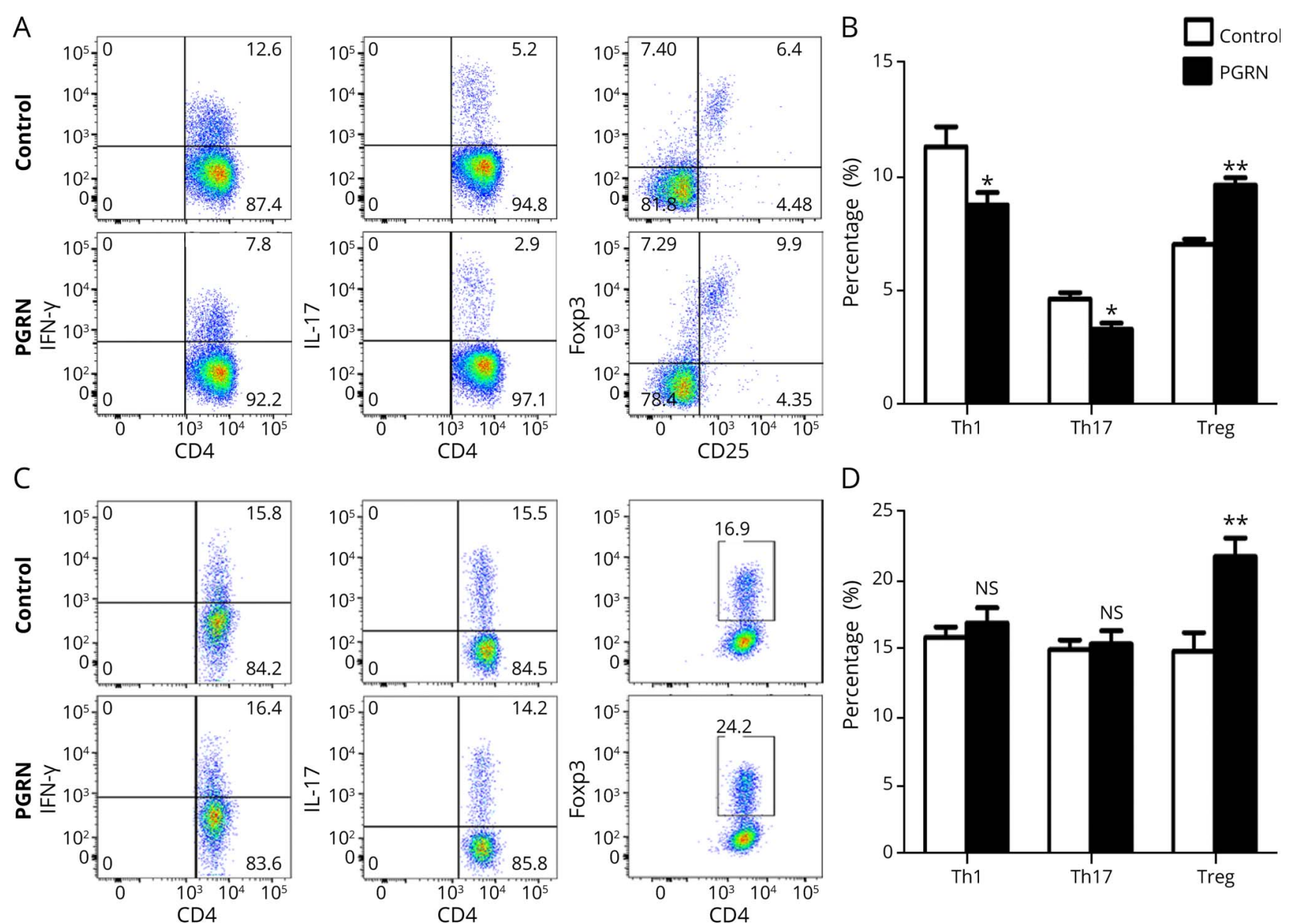

D

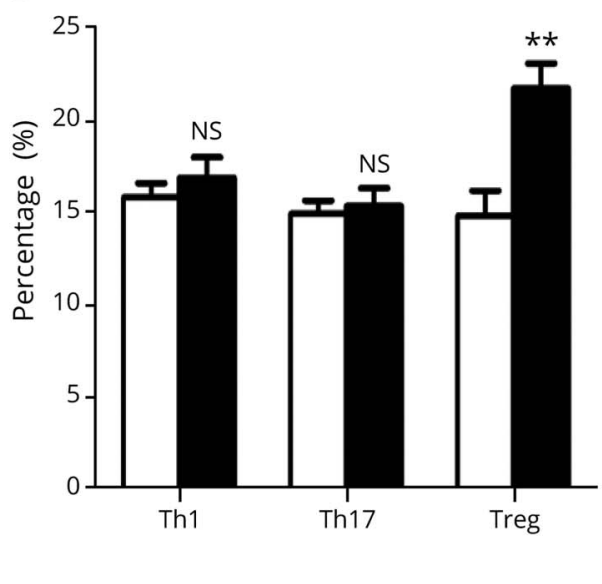

( $A$ and $B$ ) Spleen cells from EAU mice were stimulated with IRBP ${ }_{651-670}$ in the presence or absence of rPGRN for 72 hours and then assessed for intracellular expression of IFN-y, IL-17, and Foxp3 by CD4 ${ }^{+}$T cells by flow cytometry $(n=8)$. (A) Representative flow cytometry dot plots. (B) Histograms of IFN-y, IL-17, and Foxp3 by CD4 ${ }^{+} T$ cells (Th1, Th17, and Treg, respectively). (C and D) Naive CD4 ${ }^{+}$T cells from spleen cells of normal C57BL/6 mice were stimulated with Th1, Th17, and Treg cell polarization conditions in the presence or absence PGRN for 72 hours and then assessed for intracellular expression of IFN-y, IL-17, and Foxp3 by CD4 ${ }^{+}$T cells by flow cytometry $(n=8)$. (C) Representative flow cytometry dot plots of the 2 groups. (D) Histograms of Th1, Th17, and Treg of the 2 groups. Data are shown as mean \pm SEM from 2 independent experiments. ${ }^{*} p<0.05$, $* * p<0.01$, and NS, not significant. EAU = experimental autoimmune uveitis; IL = interleukin; IFN = interferon; PGRN = progranulin; RT-PCR = real-time PCR; Th = T helper; Treg = regulatory $\mathrm{T}$.

EAE mice (Figure 6C and eFigure 10A, links.lww.com/NXI/ A687). We investigated whether the aggravated activity in PGRN $^{-/-}$EAE mice correlated with the imbalanced regulation of Th1/Th17 and Treg cell response. The results showed that PGRN $^{-/-}$EAE mice exhibited a significantly higher frequency of $\mathrm{CD} 4^{+} \mathrm{T}$ cells (eFigure $10 \mathrm{~B}$ ), $\mathrm{IL}-17 \mathrm{~A}^{+} \mathrm{CD} 4^{+} \mathrm{T}$ cells, and IFN- $\gamma^{+} \mathrm{CD} 4^{+} \mathrm{T}$ cells and lower frequency of $\mathrm{CD} 4^{+} \mathrm{Foxp}^{+} \mathrm{T}$ cells in the CNS and spleen compared with WT EAE mice, respectively (Figure 6D and eFigure 10C). Consistent with the flow cytometric result, RT-PCR analysis showed an increased mRNA level of the proinflammatory cytokines including MCP-1, TNF $\alpha$, IL-1 $\beta$, and IL- 6 and a decreased mRNA expression of anti-inflammatory cytokines such as TGF- $\beta$ and IL-10 in the spinal cord from PGRN ${ }^{-/-}$ EAE mice (eFigure 10D).

\section{PGRN Skews the Balance of Macrophage Polarization From $\mathrm{M} 1$ to $\mathrm{M} 2$ in EAE}

A further study was designed to detect whether PGRN deficiency in EAE could lead to the imbalance of macrophage subtype. We investigated the frequency of M1 and M2 macrophages in the CNS and spleen from $\mathrm{PGRN}^{-/-} \mathrm{EAE}$ mice in vivo. The results showed that $\mathrm{PGRN}^{-/}$EAE mice had an increased frequency of $\mathrm{CD} 11 \mathrm{~b}^{+} \mathrm{F} 4 / 80^{+}$macrophages in the CNS and spleen compared with WT EAE mice (Figure 7A). $\mathrm{PGRN}^{-/-}$EAE mice showed an upregulated level of M1 surface molecules including MHC-II and CD86, and a downregulated expression of M2 surface molecule CD206 on the $\mathrm{CD} 11 \mathrm{~b}^{+} \mathrm{F} 4 / 80^{+}$macrophages from the CNS and spleen, respectively. An increased expression of CD40 was only found in the CNS but not in the spleen from PGRN ${ }^{-/-}$EAE mice 

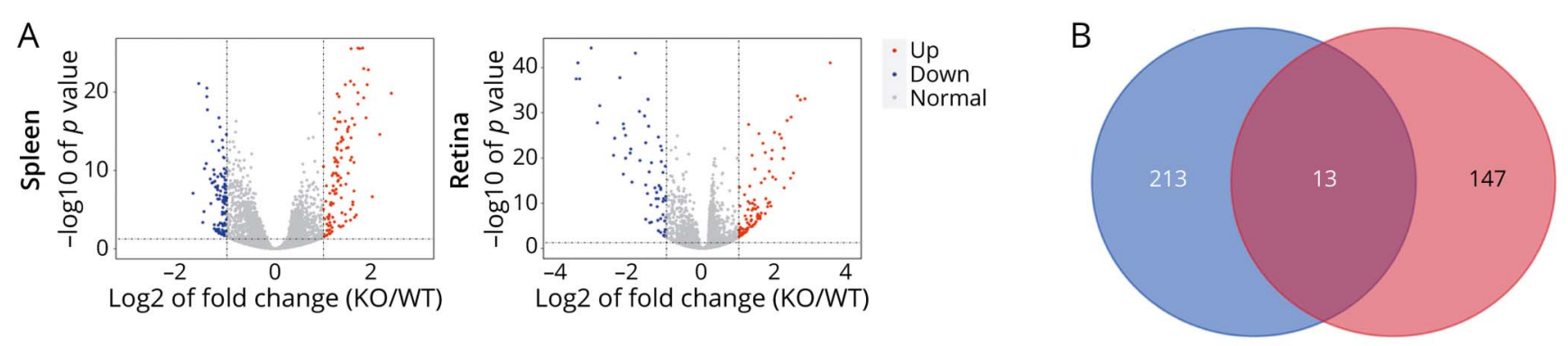

\section{Spleen GSEA (KEGG list) \\ KEGG_MAPK_SIGNALING_PATHWAY}
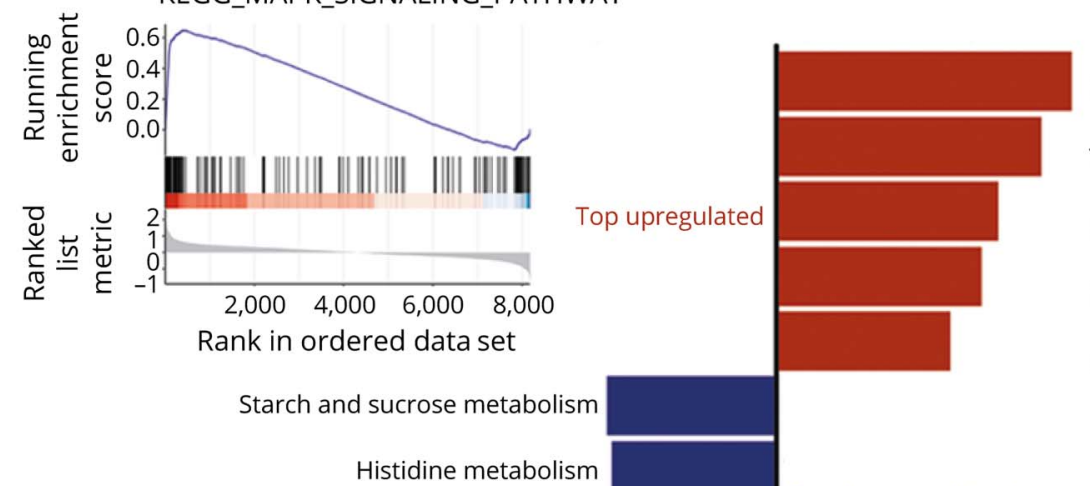

MAPK signaling pathway

TNF signaling pathway

Pathways in cancer

Focal adhesion

Regulation of actin cytoskeleton

Starch and sucrose metabolism

Histidine metabolism

Leukocyte transendothelial migration

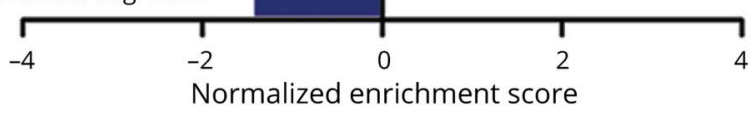

D. Retina GSEA (KEGG list)

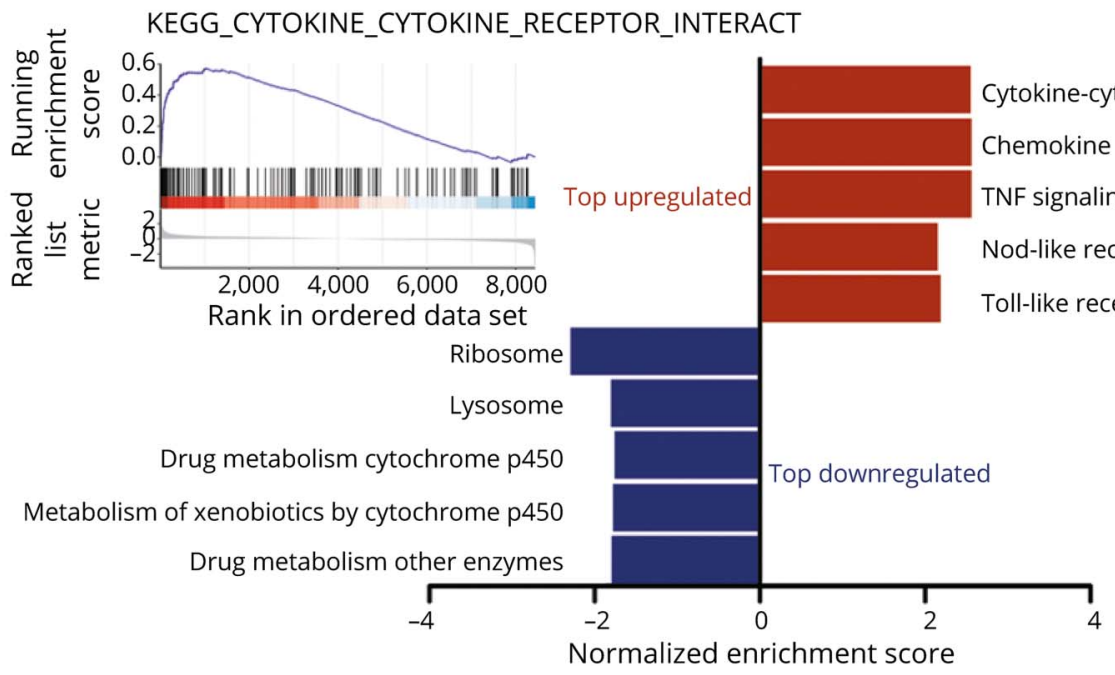

(A) Volcano plots showed DEGs in the spleen and retina between the PGRN ${ }^{-1-}$ EAU group (knockout $\left.(K O) n=4\right)$ and the WT EAU group (WT $\left.n=4\right)$. The red dots represent upregulated DEGs, whereas the blue dots represent the downregulated DEGs. Nonchanged genes are shown in gray color. (B) Venn diagram showed the shared 13 DEGs both in the spleen and in the retina. (C and D) The bar graphs showed normalized enrichment scores of GSEA on KEGG gene sets for RNA-seq analysis in the (C) spleen and (D) retina between WT and PGRN ${ }^{-1-}$ EAU group. The figure presented the top 5 of significant gene sets (FDR $\left.<0.05\right)$. Upregulated and downregulated gene sets are highlighted in red and blue, respectively. In the spleen, there were only 3 downregulated gene sets. Upper left of the figure shows the enrichment plot of MAPK signaling pathway and cytokine-cytokine receptor interaction gene sets, respectively. DEG = differentially expressed genes; EAU = experimental autoimmune uveitis; FDR = false discovery rate; GSEA = gene set enrichment analysis; PGRN = progranulin; WT = wild type.

(Figure 7, B and C). We further investigated whether PGRN could directly regulate the polarization of macrophages in vitro. Inducible nitric oxide synthase (iNOS) and arginase 1
(Arg-1), 2 important enzymes of arginine metabolism pathway, were used in the evaluation of M1 and M2 macrophage levels. ${ }^{23}$ The results showed that PGRN inhibited the mRNA 
A

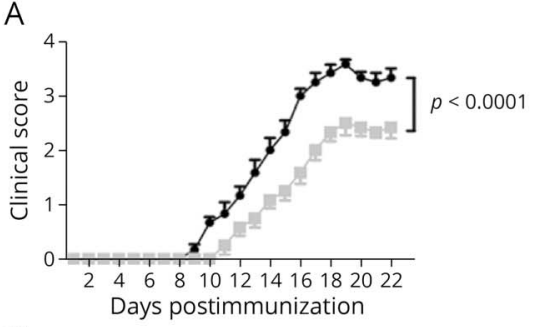

C

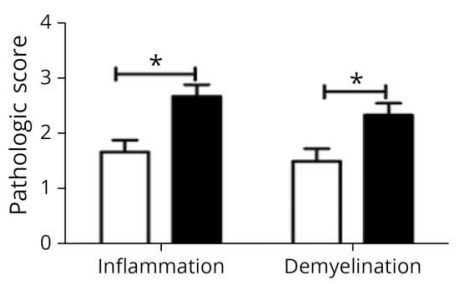

B

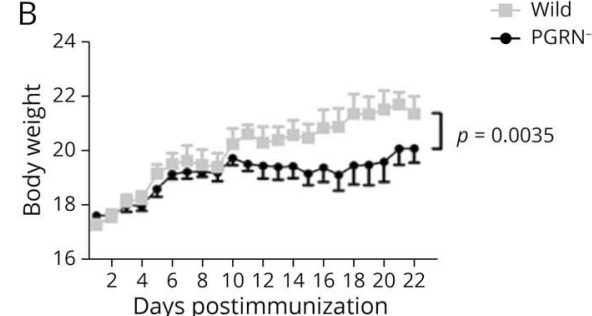

D

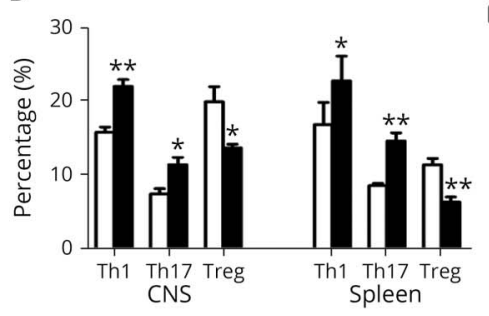

WT and PGRN ${ }^{-1-}$ mice of C57BL/6 background were induced for EAE. (A and B) Quantification of clinical score and body weight of the 2 groups from day 7 to day 22. (C) Quantification of inflammation and demyelination of the spinal cord from the 2 EAE mice groups at day 22 postimmunization and hematoxylin and eosin staining of the spinal cord sections for analyzing the degree of inflammation. Luxol fast blue staining of spinal cord sections for analyzing the degree of demyelination. (D) Quantitative analysis the frequency of IFN- $\mathrm{y}^{+} \mathrm{CD}^{+} \mathrm{T}$ cells (Th1), IL-17 $7^{+} \mathrm{CD} 4^{+}$T cells (Th17), and Foxp3 ${ }^{+} \mathrm{CD} 4^{+}$ $\mathrm{T}$ (Treg) cells in the CNS (brain and spinal cord) and spleen by flow cytometry. Data are shown as mean \pm SEM from 3 independent experiments with a total of at least 10 mice per group. $* p<0.05, * * p<0.01$. EAA = experimental autoimmune encephalomyelitis; $I \mathrm{~L}=$ interleukin; IFN = interferon; PGRN = progranulin; $\mathrm{Th}=\mathrm{T}$ helper; Treg = regulatory $\mathrm{T} ; \mathrm{WT}=$ wild type . expression of iNOS on M1 polarizing conditions and promoted the mRNA expression of Arg-1 on M2 polarizing conditions (Figure 7D).

\section{Discussion}

Previous studies have shown that PGRN has different roles in various autoimmune disease models. In this study, we demonstrate its protective effect on Th1- and Th17mediated inflammatory diseases from the following areas. First, we revealed a decreased expression of PGRN in patients with active VKH and active BD. Second, we found an increased expression of PGRN during EAU, suggesting a possible inhibitory effect for this model. Third, experiments with PGRN administration or $\mathrm{PGRN}^{-/}$mice showed that it could significantly inhibit EAU severity and regulate the differentiation of Th1, Th17, and Treg cells in vivo and in vitro. Fourth, RAN sequencing and bioinformatic analysis revealed that 5 shared upregulated hub genes and the most significantly enriched MAPK and TNF signaling pathway were involved in the exacerbation of EAU in $\mathrm{PGRN}^{-/-}$mice. Finally, using EAE, an important model for MS, we demonstrated that PGRN could also significantly inhibit inflammatory activity in association with downregulation of Th1 and Th17 cell response and upregulation of Treg cell response in the spleen and CNS. Of interest, we also found a substantial effect of PGRN on the skew from M1 to M2 polarization. Collectively, our study revealed an important negative effect of PGRN on Th1/Th17-mediated uveitis and autoimmune neuroinflammation.

PGRN has been known as a critical molecule in the regulation of autoimmune response. In this study, we first investigated whether there was an abnormal expression of PGRN in patients with uveitis. We detected PGRN expression in patients with active $\mathrm{BD}$ or $\mathrm{VKH}$ and found its downregulation in both diseases. These results suggest that PGRN could be potentially involved in these 2 diseases. However, our results are contrary to those described in previous reports showing an elevated expression of PGRN in the inflammatory disorders, such as systemic lupus erythematosus, rheumatoid arthritis, and inflammatory bowel disease. ${ }^{24-26}$ This discrepancy concerning the expression of PGRN may be owning to the difference of disease type, inflammatory activity state, and medication used when sampling.

In view of the decreased expression of PGRN in human noninfectious uveitis, we then dynamically evaluated the expression and the effect of PGRN in EAU mice. The results showed that the expression of PGRN in the retina was significantly correlated with the severity of EAU. This result suggests that a feedback inhibitory mechanism is initiated during EAU and eventually leads to resolution of the inflammation. Our study with administration and deficiency of PGRN revealed a protective effect of this molecule on EAU. These results are in line with previous reports that also showed its immune regulatory effect on autoimmune mouse models such as dextran sulfate sodium or picrylsulfonic acid-induced colitis, ${ }^{25}$ osteoarthritis, ${ }^{27}$ and collagen-induced arthritis. ${ }^{14}$ However, PGRN has been reported to play a proinflammatory role in some disease models such as systemic lupus erythematosus. ${ }^{15,28}$ These findings suggest that PGRN exerts complex immune regulatory function and may contribute different effects under different physiopathologic conditions.

Previous studies showed Th1 and Th17 cells play a critical role in the development of EAU, 7,22 and the aforementioned results showed a protective role of PGRN in EAU. Our further study was designed to investigate whether PGRN exerted its role through inhibiting Th1 and Th17 cells. The in vivo experiments using both administration and deficiency of PGRN 

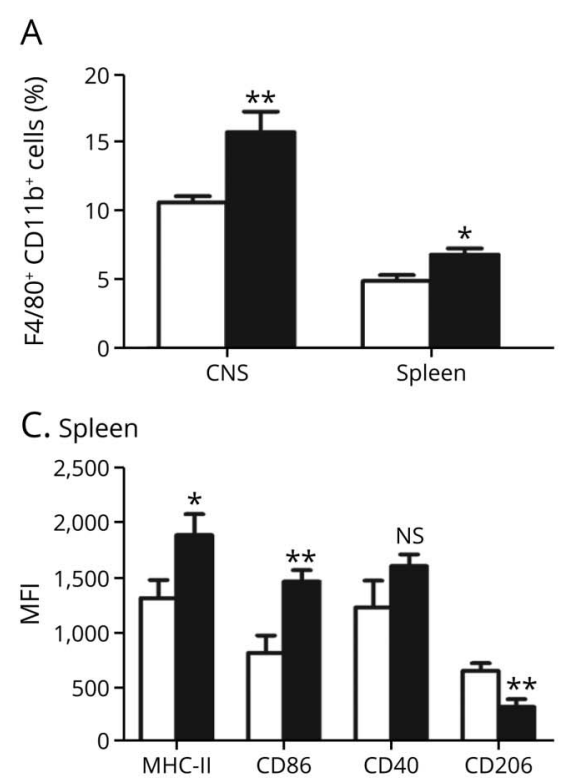
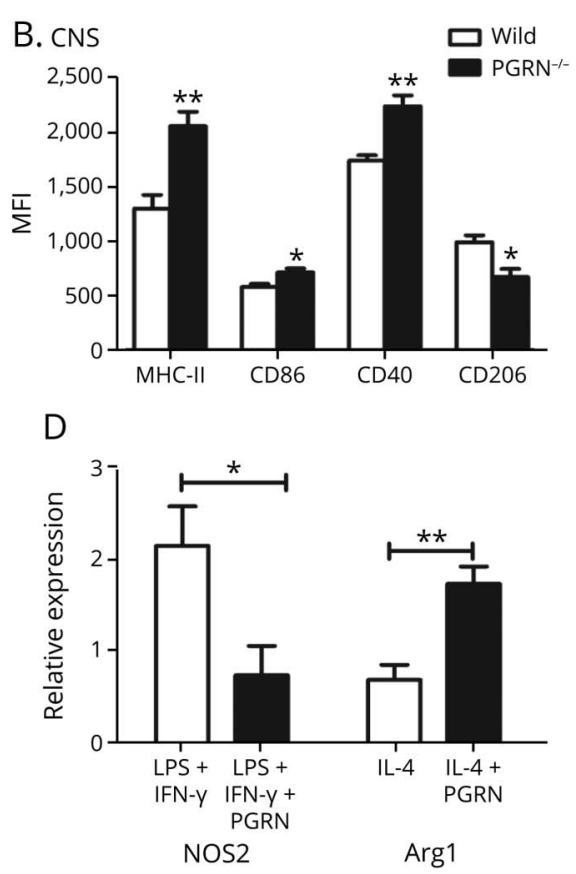

(A and B) Mononuclear cells were harvested from the CNS or spleen from PGRN ${ }^{-1-}$ EAE mice and control EAE mice on day 22; then, the cells were stained for CD11b, F4/80, MHC-II, CD86, CD40, and CD206 (6 mice per group). (A) Flow cytometric analysis of the frequency of CD $11 \mathrm{~b}^{+} \mathrm{F} 4 / 80^{+}$macrophages in the CNS and spleen, respectively. (B and C) Flow cytometric analysis of the expression of MHC-II, CD86, CD40, and CD206 on the CD11 $\mathrm{b}^{+} \mathrm{F} 4 / 80^{+}$cells in the CNS and spleen, respectively. (D) Bone marrow cells were cultured with the M-CSF for 7 days and then stimulated with or without PGRN on $\mathrm{M} 1$ or $\mathrm{M} 2$ polarizing conditions for another 2 days; then, the cells were analyzed for the expression of iNOS and Arg-1 by real-time PCR $(n=$ 6). ${ }^{*} p<0.05,{ }^{* *} p<0.01$; NS = not significant. Arg$1=$ arginase $1 ; \mathrm{EAE}=$ experimental autoimmune encephalomyelitis; iNOS = inducible nitric oxide synthase; PGRN = progranulin. demonstrated that PGRN had a negative regulation effect on these 2 cell populations. Treg cells have been reported to downregulate the inflammation in EAU and promote its resolution. $^{29,30} \mathrm{We}$ also performed several experiments to investigate whether PGRN exerts its protective role in EAU through upregulating Treg cells. The in vitro experiments showed that PGRN could induce the $\mathrm{IRBP}_{651-670^{-}}$-specific Treg cells in spleen cells from EAU mice and induce Treg cell differentiation from naive $\mathrm{CD}^{+} \mathrm{T}$ cells of normal C57BL/6 mice on polarizing conditions. The in vivo experiments with $\mathrm{PGRN}^{-/-}$mice showed that the deficiency of PGRN led to an exacerbated EAU in association with a significantly decreased frequency of Treg cell population and decreased expression of IL-10 and Foxp3. A similar result was also observed in the experiment with EAE. All these results showed that PGRN could upregulate Treg cells. Our results are in line with previous reports that showed that the deficiency of PGRN resulted in a significant reduction of Treg cells in the models of experimental dermatitis and collagen-induced inflammatory arthritis. ${ }^{31,32}$ However, no effect was observed in the experiment with intraperitoneal injection of PGRN on EAU. The reasons as to this paradoxical result are not known. A low-dose injection of rPGRN as used in this study or degradation of this protein from unknown mechanism after intraperitoneal injection may be responsible for this result. Studies are needed to clarify this issue in future.

To further shed light on the mechanism underlying PGRN's action, RNA-seq was performed. We identified 24 hub genes in the spleen and 23 hub genes in the retina. The expression of shared hub genes including Tnf, Il6, Il1b, $\mathrm{Cxcl} 2$, and $\mathrm{Ccl} 2$ in both the spleen and the retina was all increased in $\mathrm{PGRN}^{-/-}$ EAU, which were further verified by RT-PCR. These results suggested that the upregulated 5 hub genes may play a critical role in the aggravation of EAU induced in $\mathrm{PGRN}^{-/-}$mice. These results are generally consistent with previous studies whereby macrophages from PGRN-deficient mice released more inflammatory cytokines including MCP-1, CXCL1, IL6, and $\mathrm{TNF}^{33}$

Our further GO enrichment analysis indicated that the enriched GO terms both in the spleen and in the retina were mostly involved in inflammatory response, immune response, and signaling pathway transduction. These results suggest that PGRN may be involved in these physiopathologic processes, which are in line with the previous studies on the function of PGRN. ${ }^{34-36}$ We also identified that TNF signaling pathway was the shared most significantly enriched pathway for the DEGs in both the spleen and the retina. This result is consistent with previous study whereby PGRN exhibited immune regulatory function through blocking the effect of TNFa. ${ }^{27,35}$ Therefore, it is reasonable to presume that PGRN deficiency leads to an activation of TNF signaling pathway and, in turn, exacerbates EAU in the PGRN ${ }^{-/-}$mice. GSEA and KEGG analysis showed that another important signaling pathway most significantly enriched in the spleen is MAPK signaling pathway. Flow cytometry verified this result. This result is, by and large, in line with a report concerning the inhibition of PGRN on TNF $\alpha$-induced phosphorylation of $\mathrm{p} 38, \mathrm{JNK}$, and ERK1/2. ${ }^{14}$ Collectively, the bioinformatical analysis and subsequent verification suggest that MAPK signaling pathway was involved in the more severe inflammation in $\mathrm{PGRN}^{-/}$EAU mice. 
As EAE shares similar immunopathogenic features with EAU, and PGRN exerts a protective role in EAU, we performed a study to investigate whether PGRN was also involved in the development of EAE. Consistently, we revealed an inhibitory effect of PGRN on EAE clinically and pathologically in association with a downregulation of Th1 and Th17 cell response and upregulation of Treg cell response. It has been reported that $\mathrm{GRN}^{-/-}$mice were resistant to EAE. ${ }^{37}$ A paradoxical result was also observed in their experiment. The deletion of PGRN by monoclonal antibody could lead to an aggravation of EAE. Our study showed that $\mathrm{PGRN}^{-/-}$mice displayed a more severe EAE activity. The discrepancy concerning the effect of PGRN deficiency on EAE may be owing to the different doses used in the induction of EAE or different immunization protocols used in both experiments. More studies are needed to clarify the exact role of PGRN in EAE under different conditions. In addition, our in vivo and vitro experiments showed that PGRN could inhibit M1 differentiation but improve M2 polarization. It has been well known that M1 mainly exert proinflammatory role by inducing Th1/Th17-steering cytokines, whereas M2 macrophages primarily play anti-inflammatory effect through inducing $\mathrm{IL}-10$ and TGF- $\beta$ production. ${ }^{38}$ These results showed that PGRN may exert its regulatory function through modulating the balance of $\mathrm{M} 1$ and $\mathrm{M} 2$ macrophage phenotypes.

In this study, we demonstrated an inhibitory effect of PGRN on EAU up to 13 days and EAE activity up to 22 days via observation of these models in PGRN ${ }^{-/-}$and WT mice. However, it is not clear whether the deficiency of PGRN could lead to a longer or more chronic inflammation in these 2 models. More studies are needed to address this issue. A checkboard experiment, in which injection of $\mathrm{T}$ cells from the $\mathrm{PGRN}^{-/-}$vs WT mice in same number after activation into $\mathrm{WT}$ vs $\mathrm{PGFN}^{-/}$recipients, is expected to provide more evidence to the protective role of PGRN on EAU and EAE.

It has been reported that PGRN deficiency could lead to neurodegeneration in the brain, and Th17 cells are involved in the degeneration of motor neurons. ${ }^{39,40}$ Studies also have shown that PGRN is expressed by microglia and its deficiency may give birth to an aberrant increase in phagocytosis and lysosome function, ${ }^{39}$ as well as the transition from homeostatic to diseasespecific state of microglia. ${ }^{41,42}$ Collectively, these results suggest an important role of PGRN in the modulation of neurodegeneration and neuroinflammatory diseases. Elucidation of the modulating mechanisms of PGRN in the neurodegeneration and neuroinflammation may provide new insight onto the target for the studies on prevention and treatment of these diseases.

Collectively, the present study shows that PGRN may play a protective role both in EAU and EAE through inhibiting autoreactive Th1 and Th17 cell response and inducing the expansion of Treg cells. Of interest, we also revealed that it could also exert its role through promoting the polarization of M2 macrophages in EAE model. These results suggest that PGRN could act as therapeutic target in study on the prevention and treatment of Th1/Th17-mediated autoimmune diseases.

\section{Study Funding}

This work was supported by National Natural Science Foundation Project (81800813), Natural Science Foundation Major International (Regional) Joint Research Project (81720108009), National Natural Science Foundation Key Program (81930023), Chongqing Key Project (CSTC2021jscx-gksb-N0010), Chongqing Outstanding Scientists Project (2019), Chongqing Key Laboratory of Ophthalmology (CSTC, 2008CA5003), Chongqing Science \& Technology Platform and Base Construction Program (cstc2014pt-sy10002), and the Chongqing Chief Medical Scientist Project (2018).

\section{Disclosure}

The authors declare that no conflict of interest exists. Go to Neurology.org/NN for full disclosures.

\section{Publication History}

Received by Neurology: Neuroimmunology \& Neuroinflammation June 15, 2021. Accepted in final form November 24, 2021.

Appendix Authors

\begin{tabular}{|c|c|c|}
\hline Name & Location & Contribution \\
\hline $\begin{array}{l}\text { Chaokui } \\
\text { Wang, } \\
\text { PhD }\end{array}$ & $\begin{array}{l}\text { The First Affiliated Hospital of } \\
\text { Chongqing Medical University, } \\
\text { Chongqing Key Lab of } \\
\text { Ophthalmology, Chongqing } \\
\text { Eye Institute, Chongqing } \\
\text { Branch of National Clinical } \\
\text { Research Center for Ocular } \\
\text { Diseases, China }\end{array}$ & $\begin{array}{l}\text { Drafting/revision of the } \\
\text { manuscript for content, } \\
\text { including medical } \\
\text { writing for content; } \\
\text { major role in the } \\
\text { acquisition of data; } \\
\text { study concept or design; } \\
\text { and analysis or } \\
\text { interpretation of data }\end{array}$ \\
\hline $\begin{array}{l}\text { Wenjun } \\
\text { Zhou, } \\
\text { PhD }\end{array}$ & $\begin{array}{l}\text { The First Affiliated Hospital of } \\
\text { Chongqing Medical University, } \\
\text { Chongqing Key Lab of } \\
\text { Ophthalmology, Chongqing } \\
\text { Eye Institute, Chongqing } \\
\text { Branch of National Clinical } \\
\text { Research Center for Ocular } \\
\text { Diseases, China }\end{array}$ & $\begin{array}{l}\text { Drafting/revision of the } \\
\text { manuscript for content, } \\
\text { including medical writing for } \\
\text { content; major role in the } \\
\text { acquisition of data; study } \\
\text { concept or design; and } \\
\text { analysis or interpretation of } \\
\text { data }\end{array}$ \\
\hline $\begin{array}{l}\text { Guannan } \\
\text { Su, PhD }\end{array}$ & $\begin{array}{l}\text { The First Affiliated Hospital of } \\
\text { Chongqing Medical University, } \\
\text { Chongqing Key Lab of } \\
\text { Ophthalmology, Chongqing } \\
\text { Eye Institute, Chongqing } \\
\text { Branch of National Clinical } \\
\text { Research Center for Ocular } \\
\text { Diseases, China }\end{array}$ & $\begin{array}{l}\text { Major role in the acquisition of } \\
\text { data and analysis or } \\
\text { interpretation of data }\end{array}$ \\
\hline $\begin{array}{l}\text { Jianping } \\
\mathrm{Hu}\end{array}$ & $\begin{array}{l}\text { The First Affiliated Hospital of } \\
\text { Chongqing Medical University, } \\
\text { Chongqing Key Lab of } \\
\text { Ophthalmology, Chongqing } \\
\text { Eye Institute, Chongqing } \\
\text { Branch of National Clinical } \\
\text { Research Center for Ocular } \\
\text { Diseases, China }\end{array}$ & $\begin{array}{l}\text { Major role in the acquisition of } \\
\text { data and analysis or } \\
\text { interpretation of data }\end{array}$ \\
\hline $\begin{array}{l}\text { Peizeng } \\
\text { Yang, } \\
\text { PhD }\end{array}$ & $\begin{array}{l}\text { The First Affiliated Hospital of } \\
\text { Chongqing Medical University, } \\
\text { Chongqing Key Lab of } \\
\text { Ophthalmology, Chongqing } \\
\text { Eye Institute, Chongqing } \\
\text { Branch of National Clinical } \\
\text { Research Center for Ocular } \\
\text { Diseases, China }\end{array}$ & $\begin{array}{l}\text { Drafting/revision of the } \\
\text { manuscript for content, } \\
\text { including medical writing for } \\
\text { content; major role in the } \\
\text { acquisition of data; study } \\
\text { concept or design; and } \\
\text { analysis or interpretation of } \\
\text { data }\end{array}$ \\
\hline
\end{tabular}




\section{References}

1. Munoz-Fernandez S, Martin-Mola E. Uveitis. Best Pract Res Clin Rheumatol. 2006; 20(3):487-505

2. Tsirouki T, Dastiridou A, Symeonidis C, et al. A focus on the epidemiology of uveitis. Ocul Immunol Inflamm. 2018;26(1):2-16.

3. Caspi RR. A look at autoimmunity and inflammation in the eye. J Clin Invest. 2010; 120(9):3073-3083.

4. Chi W, Zhou S, Yang P, Chen L. CD4(+) T cells from behcet patients produce high levels of IL-17. Eye Sci. 2011;26(2):65-69.

5. Chi W, Zhu X, Yang P, et al. Upregulated IL-23 and IL-17 in Behcet patients with active uveitis. Invest Ophthalmol Vis Sci. 2008;49(7):3058-3064.

6. Chen L, Yang P, Zhou H, et al. Diminished frequency and function of CD4+CD25high regulatory $\mathrm{T}$ cells associated with active uveitis in Vogt-Koyanagi-Harada syndrome. Invest Ophthalmol Vis Sci. 2008;49(8):3475-3482.

7. Luger D, Silver PB, Tang J, et al. Either a Th17 or a Th1 effector response can drive autoimmunity: conditions of disease induction affect dominant effector category. J Exp Med. 2008;205(4):799-810.

8. Correale J, Gaitan MI, Ysrraelit MC, Fiol MP. Progressive multiple sclerosis: from pathogenic mechanisms to treatment. Brain. 2017;140(3):527-546.

9. Chu F, Shi M, Lang Y, et al. Adoptive transfer of immunomodulatory M2 macrophages suppresses experimental autoimmune encephalomyelitis in C57BL/6 mice via blockading NF-kappaB pathway. Clin Exp Immunol. 2021;204(2):199-211.

10. Veremeyko T, Yung AWY, Dukhinova M, et al. Cyclic AMP pathway suppress autoimmune neuroinflammation by inhibiting functions of encephalitogenic CD4 $\mathrm{T}$ cells and enhancing M2 macrophage polarization at the site of inflammation. Front Immunol. 2018;9:50.

11. Daniel R, Daniels E, He Z, Bateman A. Progranulin (acrogranin/PC cell-derived growth factor/granulin-epithelin precursor) is expressed in the placenta, epidermis, microvasculature, and brain during murine development. Dev Dyn. 2003;227(4):593-599.

12. Bateman A, Bennett HP. The granulin gene family: from cancer to dementia. Bioessays. 2009;31(11):1245-1254.

13. Feng JQ, Guo FJ, Jiang BC, et al. Granulin epithelin precursor: a bone morphogenic protein 2 -inducible growth factor that activates Erk1/2 signaling and JunB transcription factor in chondrogenesis. FASEB J. 2010;24(6):1879-1892.

14. Tang W, Lu Y, Tian QY, et al. The growth factor progranulin binds to TNF receptors and is therapeutic against inflammatory arthritis in mice. Science. 2011;332(6028): 478-484.

15. Chen X, Wen Z, Xu W, Xiong S. Granulin exacerbates lupus nephritis via enhancing macrophage M2b polarization. PLoS One. 2013;8(6):e65542.

16. Yang P, editor. Atlas of Uveitis: Diagnosis and Treatment. Springer Nature Singapore Pte Ltd.; 2021:411-537.

17. McGinley AM, Edwards SC, Raverdeau M, Mills KHG. Th17 cells, $\gamma \delta$ T cells and their interplay in EAE and multiple sclerosis. J Autoimmun. 2018; 87(2018):97-108.

18. Criteria for diagnosis of Behcet's disease. International Study Group for Behcet's Disease. Lancet. 1990;335(8697):1078-1080.

19. Yang P, Zhong Y, Du L, et al. Development and evaluation of diagnostic criteria for Vogt-Koyanagi-Harada disease. JAMA Ophthalmol. 2018;136(9):1025-1031.

20. Read RW, Holland GN, Rao NA, et al. Revised diagnostic criteria for Vogt-KoyanagiHarada disease: report of an international committee on nomenclature. Am J Ophthalmol. 2001;131(5):647-652.

21. Percie du Sert N, Hurst V, Ahluwalia A, et al. The ARRIVE Guidelines 2.0: updated guidelines for reporting animal research. Br J Pharmacol. 2020;177(16):3617-3624.
22. Amadi-Obi A, Yu CR, Liu X, et al. TH17 cells contribute to uveitis and scleritis and are expanded by IL-2 and inhibited by IL-27/STAT1. Nat Med. 2007;13(6):711-718.

23. Liu C, Li Y, Yu J, et al. Targeting the shift from M1 to M2 macrophages in experimental autoimmune encephalomyelitis mice treated with fasudil. PLoS One. 2013; 8(2):e54841.

24. Tanaka A, Tsukamoto $\mathrm{H}$, Mitoma $\mathrm{H}$, et al. Serum progranulin levels are elevated in patients with systemic lupus erythematosus, reflecting disease activity. Arthritis Res Ther. 2012;14(6):R244.

25. Wei F, Zhang Y, Jian J, et al. PGRN protects against colitis progression in mice in an IL-10 and TNFR2 dependent manner. Sci Rep. 2014;4:7023.

26. Cerezo LA, Kuklova M, Hulejova $\mathrm{H}$, et al. Progranulin is associated with disease activity in patients with rheumatoid arthritis. Mediators Inflamm. 2015;2015:740357.

27. Wei JL, Fu W, Ding YJ, et al. Progranulin derivative Atsttrin protects against early osteoarthritis in mouse and rat models. Arthritis Res Ther. 2017;19(1):280.

28. Jing C, Zhang X, Song Z, Zheng Y, Yin Y. Progranulin mediates proinflammatory responses in systemic lupus erythematosus: implications for the pathogenesis of systemic lupus erythematosus. J Interferon Cytokine Res. 2020;40(1):33-42.

29. Liu YH, Molzer C, Makinen K, et al. Treatment with FoxP3+ antigen-experienced $\mathrm{T}$ regulatory cells arrests progressive retinal damage in a spontaneous model of uveitis. Front Immunol. 2020;11:2071.

30. Gery I, Caspi RR. Tolerance induction in relation to the eye. Front Immunol. 2018;9: 2304.

31. Wei F, Zhang Y, Zhao W, Yu X, Liu CJ. Progranulin facilitates conversion and function of regulatory T cells under inflammatory conditions. PLoS One. 2014;9(11):e112110.

32. Huang $\mathrm{K}$, Chen A, Zhang $\mathrm{X}$, et al. Progranulin is preferentially expressed in patients with psoriasis vulgaris and protects mice from psoriasis-like skin inflammation. Immunology. 2015;145(2):279-287.

33. Yin F, Banerjee R, Thomas B, et al. Exaggerated inflammation, impaired host defense, and neuropathology in progranulin-deficient mice. J Exp Med. 2010;207(1):117-128.

34. Guo Z, Li Q, Han Y, et al. Prevention of LPS-induced acute lung injury in mice by progranulin. Mediators Inflamm. 2012;2012:540794.

35. Zhao YP, Liu B, Tian QY, et al. Progranulin protects against osteoarthritis through interacting with TNF-alpha and beta-Catenin signalling. Ann Rheum Dis. 2015; 74(12):2244-2253.

36. Song Z, Zhang X, Zhang L, et al. Progranulin plays a central role in host defense during sepsis by promoting macrophage recruitment. Am J Respir Crit Care Med. 2016; 194(10):1219-1232.

37. Schmitz K, Wilken-Schmitz A, Vasic V, et al. Progranulin deficiency confers resistance to autoimmune encephalomyelitis in mice. Cell Mol Immunol. 2020;17(10): 1077-1091.

38. Martinez FO, Gordon S. The M1 and M2 paradigm of macrophage activation: time for reassessment. F1000Prime Rep. 2014;6:13.

39. Feng T, Mai S, Roscoe JM, et al. Loss of TMEM106B and PGRN leads to severe lysosomal abnormalities and neurodegeneration in mice. EMBO Rep. 2020;21(10): e50219.

40. Jin M, Akgun K, Ziemssen T, et al. Interleukin-17 and Th17 lymphocytes directly impair motoneuron survival of wildtype and FUS-ALS mutant human iPSCs. Int J Mol Sci. 2021;22(15):8042.

41. Zhang J, Velmeshev D, Hashimoto K, et al. Neurotoxic microglia promote TDP-43 proteinopathy in progranulin deficiency. Nature. 2020;588(7838):459-465.

42. Wang XM, Zeng P, Fang YY, Zhang T, Tian Q. Progranulin in neurodegenerative dementia. J Neurochem. 2021;158(2):119-137. 


\title{
Neurology \\ Neuroimmunology \& Neuroinflammation
}

\author{
Progranulin Suppressed Autoimmune Uveitis and Autoimmune Neuroinflammation by \\ Inhibiting Th1/Th17 Cells and Promoting Treg Cells and M2 Macrophages \\ Chaokui Wang, Wenjun Zhou, Guannan Su, et al. \\ Neurol Neuroimmunol Neuroinflamm 2022;9; \\ DOI 10.1212/NXI.0000000000001133
}

This information is current as of January 26, 2022

Updated Information \&

Services

References

Subspecialty Collections

Permissions \& Licensing

Reprints including high resolution figures, can be found at:

http://nn.neurology.org/content/9/2/e1133.full.html

This article cites 41 articles, 6 of which you can access for free at: http://nn.neurology.org/content/9/2/e1133.full.html\#\#ref-list-1

This article, along with others on similar topics, appears in the following collection(s):

All Demyelinating disease (CNS)

http://nn.neurology.org//cgi/collection/all_demyelinating_disease_cns

All Immunology

http://nn.neurology.org//cgi/collection/all_immunology

All Medical/Systemic disease

http://nn.neurology.org//cgi/collection/all_medical_systemic_disease

Autoimmune diseases

http://nn.neurology.org//cgi/collection/autoimmune_diseases

Information about reproducing this article in parts (figures,tables) or in its entirety can be found online at:

http://nn.neurology.org/misc/about.xhtml\#permissions

Information about ordering reprints can be found online:

http://nn.neurology.org/misc/addir.xhtml\#reprintsus

Neurol Neuroimmunol Neuroinflamm is an official journal of the American Academy of Neurology.

Published since April 2014, it is an open-access, online-only, continuous publication journal. Copyright

Copyright (C) 2022 The Author(s). Published by Wolters Kluwer Health, Inc. on behalf of the American

Academy of Neurology.. All rights reserved. Online ISSN: 2332-7812.

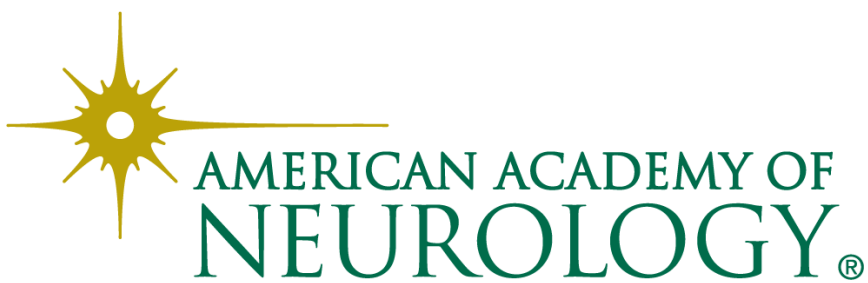

